\title{
Membrane-Based Separation of Phenol/Water Mixtures Using Ionically and Covalently Cross-Linked Ethylene-Methacrylic Acid Copolymers
}

\author{
Alexander Mixa and Claudia Staudt \\ Institute of Organic and Macromolecular Chemistry, Heinrich-Heine University of Duesseldorf, Universitaetsstr. 1, \\ 40225 Duesseldorf, Germany \\ Correspondence should be addressed to Claudia Staudt, staudt@uni-duesseldorf.de
}

Received 18 April 2008; Revised 11 September 2008; Accepted 16 November 2008

Recommended by Toshinori Tsuru

\begin{abstract}
Membrane-based separation of phenol/water mixtures with concentrations of phenol between $3 \mathrm{wt} \%$ and $8 \mathrm{wt} \%$ in the feed has been performed with nonmodified as well as cross-linked ethylene-methacrylic acid (E-MAA) copolymers with different amounts of methacrylic acid. As cross-linking agents, aluminium acetyl acetonate, which leads to ionically cross-linked membranes, and 2,3,5,6-tetramethyl-1,4-phenylene diamine and glycerine digycidether, leading to covalently cross-linked membranes, have been used. Generally, it was found that with increasing phenol content in the feed, the total flux is increasing whereas the enrichment factor is decreasing. Using nonmodified membranes with higher methacrylic acid monomer content in the polymer, lower fluxes and higher enrichment factors were observed. Investigation of different cross-linked membranes showed that with high phenol concentration in the feed, ionic cross-linking seems to be very promising. Furthermore, variation of feed temperature shows that ionically cross-linked membranes reached higher fluxes as well as higher enrichment factors at elevated temperatures. The temperature-dependent data were fitted based on an Arrhenius-type equation, and activation energies for the permeation of phenol and water through the membrane were calculated.
\end{abstract}

Copyright (c) 2008 A. Mixa and C. Staudt. This is an open access article distributed under the Creative Commons Attribution License, which permits unrestricted use, distribution, and reproduction in any medium, provided the original work is properly cited.

\section{Introduction}

In most of the processes which are carried out in the chemical industry, the desired purity of the products is not reached during the reaction process. Therefore, technical separation methods are extremely important in order to reach high-quality products in acceptable yields at low costs. Conventional methods of separating mixtures like distillation, extraction, ad- or absorption as well as crystallization processes and combinations of these methods are well established but in several cases they are cost- and energyconsumptive so that alternative methods like membranebased separations are investigated. Membrane processes offer the advantages of lower energy consumption compared to distillation as the separation of mixtures can be performed at much lower temperatures than the boiling temperatures of the components.
Development of suitable membrane materials and modules is necessary for successful competition with conventional separation methods. Processes, well established on the continuously growing membrane market, are dehydration of organic solvents by pervaporation, enrichment of oxygen from air by gas permeation, and gasoline vapour recovery by vapour permeation [1]. New fields of membrane applications are the separation of olefin/paraffins [2], the removal of di- and trinuclear aromatic components $[3,4]$ and sulphur containing aromatic components $[5,6]$ from gasoline as well as the removal of organic components as p-chloroand dichlorophenols [7], cresols, alkyl substituted phenols, and aniline derivatives [8-10] from process or waste water streams.

In particular, the removal of phenol is of great interest in waste-water treatment. With a global production of 8 million tons each year in 2001, phenol is one of the most 


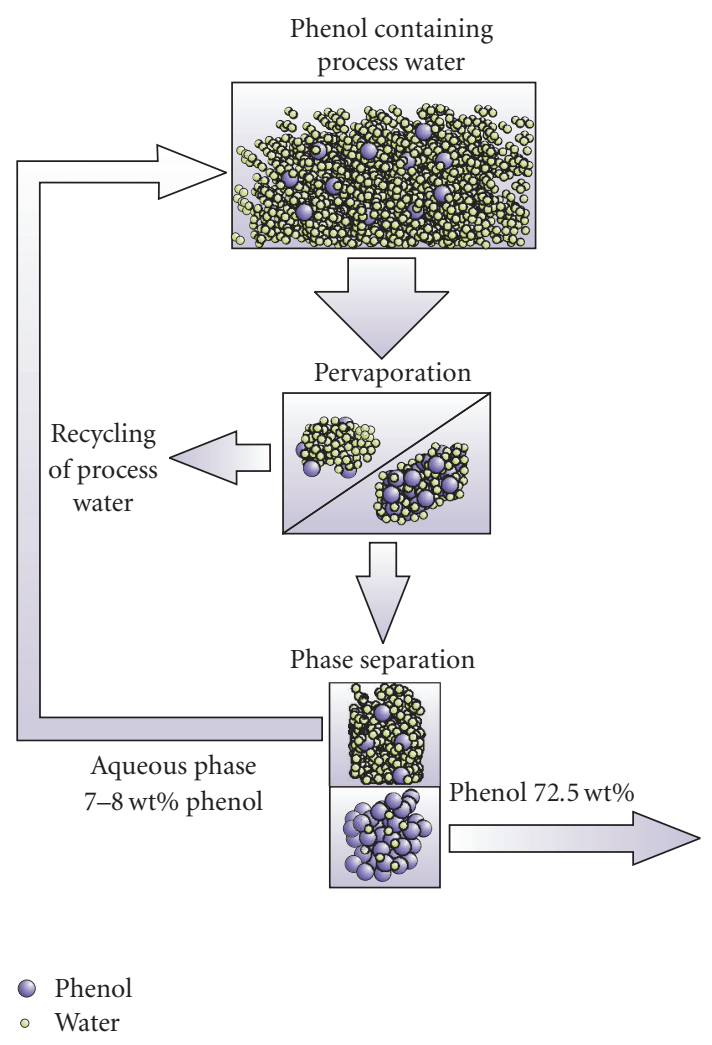

Figure 1: Process scheme for the removal of phenol from process water.

important intermediates in chemical industry. Phenol contaminated effluents arise, for example, during the production processes of bisphenol A, phenol formaldehyde resins, and the Hock process. The average concentration of phenol in these streams has been evaluated to be between $3 \mathrm{wt} \%$ and $10 \mathrm{wt} \%$ depending on temperature. For the reduction of phenol from waste water, several membrane extraction processes offer very promising separation properties $[9,11$, 12]. However, increasing prices for phenol as raw material makes it worthwhile to recycle the valuable product from the stream, which is difficult with membrane extraction processes. In order to realize an economically feasible separation process, it is favorable to combine pervaporation with other separation techniques, as shown in the hybrid process in Figure 1. Such hybrid processes have been already proposed for the separation of other organic compounds from aqueous streams. In this process, a one-step pervaporation process is combined with a liquid-liquid phase separation where the condensed permeate can be treated. The organic phase contains $72.5 \mathrm{wt} \%$ of phenol and can be worked up by conventional methods, whereas the aqueous phase, containing $7-8 \mathrm{wt} \%$ phenol, can be combined with the feed stream. The retentate of the pervaporation unit contains only a small amount of phenol, and can be reused as process water.

Among all different kinds of membrane polymers investigated for the phenol recovery from process and waste water streams, poly dimethyl siloxanes and modified structures thereof are the most frequently published ones [13-16]. For example, with a concentration of approximately $5 \mathrm{wt} \%$ of phenol in feed, a flux of $0.3 \mathrm{~kg} \cdot \mathrm{m}^{-2} \cdot \mathrm{h}^{-1}$ for a PDMS membrane of $50 \mu \mathrm{m}$ thickness was found with a selectivity of 11.6 at $70^{\circ} \mathrm{C}[15]$. With Polydimethylsiloxanimide, which is a siloxane imide copolymer at the same feed concentration, much higher fluxes but lower selectivities were found compared to pure PDMS at $60^{\circ} \mathrm{C}$. Selectivities between 18-23 and fluxes between 12.4 and $27 \mathrm{~kg} \cdot \mu \mathrm{m} \cdot \mathrm{m}^{-2} \cdot \mathrm{h}^{-1}$ have been obtained [17]. For polyimides as membrane material at a feed concentration of $7.8 \mathrm{wt} \%$ phenol at $60^{\circ} \mathrm{C}$, the selectivity reached is 7.5 and the fluxes are $14 \mathrm{~kg} \cdot \mu \mathrm{m} \cdot \mathrm{m}^{-2} \cdot \mathrm{h}^{-1}[18,19]$. For polyurethane, at the same phenol concentration in feed at $60^{\circ} \mathrm{C}$, a flux of $1.5 \mathrm{~kg} \cdot \mu \mathrm{m} \cdot \mathrm{m}^{-2} \cdot \mathrm{h}^{-1}$ was reported with a selectivity of $74[20,21]$. The ethylene methacrylic acid copolymer used in this work showed separation data and fluxes comparable to those of the polydimethylsiloxanimide.

Since the permeate is phase separated after condensation, and the aqueous phase can be recombined with the feed stream, for the hybrid process as shown in Figure 1, high flux membranes have much better application potential than high selective membrane materials.

The aim of this work was using a commercially available rubbery polymer (ethylene methacrylic acid copolymer) with functional groups, opening the opportunity of modifying the chemical structure (e.g., performing ionical or covalent cross-linking). This has been shown before for different polymer structures as a very successful method enhancing the separation characteristics as well as the chemical and thermal stability of membrane materials [2225 ]. In the case of the ethylene methacrylic acid copolymer used in this project it was even possible to use the basic polymeric material for different separation problems (e.g., aromatics/aliphatics separation as well as removal of phenol from aqueous streams applying suitable modifications) [23, $24,26]$.

\section{Theoretical Background}

\subsection{The Pervaporation Process}

Pervaporation processes are membrane-based separations of liquid mixtures as principally shown in Figure 2 [24]. Thereby a phase transfer from the liquid phase to the vaporous phase through a polymeric membrane is occuring. In this process, the liquid feed mixture to be separated flows along one side of the membrane while the various feed components are permeating into and through the membrane at different rates. Therefore, the liquid retentate leaving the unit on the same side of the membrane as the feed enters is depleted in the components permeating preferentially. Consequently, the vaporous permeate collected on the back side of the membrane is enriched in the preferentially permeating component. The driving force for the mass transport of each component, through a membrane is the difference of the chemical potential $\Delta \mu_{i}\left(T, p, x_{i}\right.$, where $i=$ $1, \ldots, n)$ of the components present in the mixture between feed and permeate side. In pervaporation, the difference in 


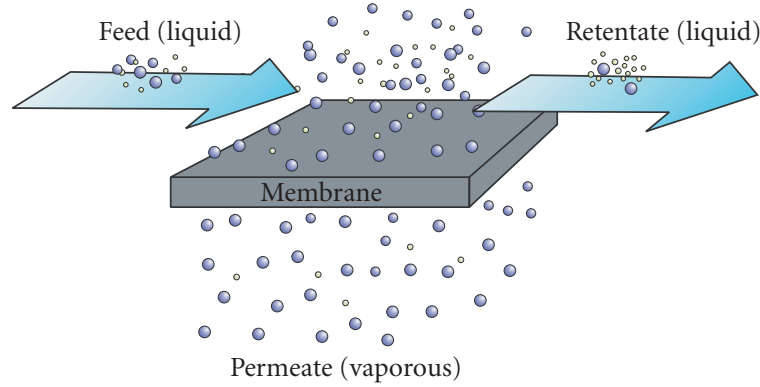

FIgure 2: Principles of pervaporation: liquid feed, liquid retentate (depleted), solution-diffusion membrane, and vaporous permeate (enriched).

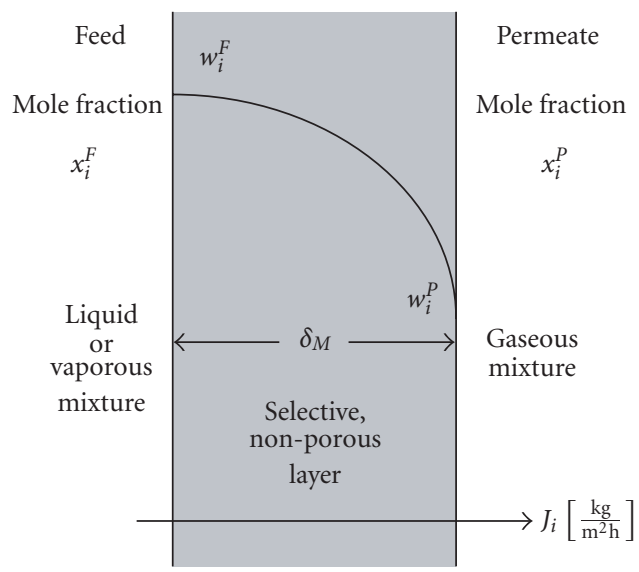

FIGURE 3: Solution-diffusion model describing mass transport through polymeric membranes.

the chemical potential is mainly achieved by keeping the permeate pressure much lower than the feed pressure.

\subsection{The Solution Diffusion Model}

Often polymeric solution-diffusion membranes are classified as "nonporous" membranes because no pores are existing, only microvoids caused by free volume compartiments of the polymer chains. However, porous membranes, which are separating mixtures based on a sieve mechanism, are moving fast in the direction of nanoporous materials and the difference between porous and nonporous membrane materials is disappearing. Therefore, it is better to classifiy the polymeric membranes used in this work as solutiondiffusion-membranes instead of nonporous membranes.

The main features of the so-called solution-diffusion model widely used to describe the mass transport in selective polymeric layers are given in Figure 3. This model not only holds for pervaporation, but also for vapor and gas permeation [27-29]. The basic assumptions of this model are the existence of the thermodynamic phase equilibrium at both boundary surfaces of the selective layer in contact with the upstream feed mixture and the downstream permeate mixture.
The diffusion process inside the selective layer is described by Fick's law, which is assumed to be valid for each component, $i=1, \ldots, n$, (see [30])

$$
J_{i}=-D_{i}\left(w_{i}, \ldots, w_{n}\right) \rho_{M} \frac{d w_{i}}{d z}
$$

where $J_{i}$ is the mass flux, $D_{i}$ is the diffusion coefficient, $z$ is the coordinate perpendicular to the membrane surface, and $\rho_{M}$ is the density of the selective polymer layer. The concentration of each component in this polymer layer is given by its weight fraction $w_{i}$, defined as

$$
w_{i}=\frac{m_{i}}{m_{M}+\sum_{j=1}^{n} m_{j}},
$$

where $m_{i}$ and $m_{j}$ are the masses of the various components dissolved and $m_{M}$ is the mass of the polymer. Under steadystate conditions, integration of (1) gives

$$
J_{i}=\frac{\rho_{M}}{\delta_{M}} \int_{w_{i}^{p}}^{w_{i}^{F}} D_{i}\left(w_{i}, \ldots, w_{n}\right) d w_{i},
$$

with $\delta_{M}$ being the thickness of the selective layer, while $w_{i}^{F}$ and $w_{i}^{P}$ are the weight fractions of the component $i$ in the selective layer in its boundary at the feed side and the permeate side, respectively. These fractions depend on the composition of the corresponding mixture in contact with the boundary. Generally, $D_{i}$ depends on the weight fraction of each component permeating and consequently, the mass fluxes $J_{i}$ are mutually dependent.

With (3), $J_{i}$ of any component permeating can be calculated for a given feed concentration if the solubilities $w_{i}^{F}$ and $w_{i}^{P}$, the dependency of the diffusion coefficient $D_{i}$ on composition, the thickness $\delta_{M}$, and the density $\rho_{M}$ are known at operating conditions.

The weight fraction $w_{i}^{P}$ of any component $i$ in the permeate is given by the ratio of partial molar flux $J_{i \text { (partial) }}$ to the total molar flux $J_{\text {total }}$,

$$
w_{i}^{P}=\frac{J_{i}}{J_{\text {total }}} .
$$

In many cases, modeling of the mass transport through membrane materials for better understanding of the factors influencing the transport is difficult although the approaches have been strongly improved in the last ten years [31, 32]. The reason for this is that, for example, experimentally it is not possible to measure concentration-dependent diffusion coefficients in mixtures and furthermore the thickness and density of the membranes are strongly depending on operating conditions, where in many cases swelling of the membrane is occurring. It has been also shown that solubility measurements will not lead to better understanding of the separation performance of different types of polymers since according to Figure 3 only solubliliy experiments representing the steady-state on the feed side and vapour sorption experiments representing the case on the permeate side can be performed. From these experiments no information is obtained about how the concentration gradient is changing in the polymer layer, if capillary condensation, for example, 
occurs with high boiling components, or how swelling is influencing the membrane microstructure.

In order to obtain realistic results about the membrane performances for different ethylene-methacrylic acid copolymers, in this work concentration- and temperaturedependent pervaporation experiments have been performed and discussed from the point of view of potential industrial application.

\subsection{Membrane Separation Characteristics}

The separation performance of a membrane material is characterized by two parameters, the permeability which gives an impression on the mass transport through the membrane material and the selectivity which shows the quality of separation The permeability can be measured by the mass flux through the membrane. The flux is normalized by the membrane area, the membrane thickness, and the time, so that its unit is $\mathrm{kg} \cdot \mu \mathrm{m} \cdot \mathrm{m}^{-2} \cdot \mathrm{h}^{-1}$.

In order to compare the quality of separation for the different membranes according to [33] either the enrichment factor $\beta$ which is the ratio of the weight fraction in permeate and feed respectively of the preferred permeating component can be used or the separation factor $\alpha$, which is used in this work as defined in the following equation:

$$
\alpha=\frac{\left(w_{i} / w_{j}\right)^{\text {permeate }}}{\left(w_{i} / w_{j}\right)^{\text {feed }}} .
$$

Here $w_{i}, w_{j}$ are the weight fractions of the components ( $i$ is the preferentially permeating component) in the permeate and feed, respectively.

If pervaporation experiments are performed at different feed temperatures using the same feed mixture, generally with increasing temperature increasing fluxes are obtained. In many cases an exponential dependency of total as well as partial fluxes from the temperature are observed. According to (6), activation energies for the permeation of the single components as well as for the mixture through the membrane material can be calculated,

$$
J=J_{0} \cdot \delta_{M} \cdot \exp \left(-\frac{E_{J}}{R T}\right),
$$

thereby $J_{0}$ is a pre-exponential factor, $\delta_{M}$ is the thickness of the dry membrane $[\mu \mathrm{m}], E_{J}$ is the activation energy $\left[\mathrm{kJ} \mathrm{mol}{ }^{-1}\right], R$ is the common gas constant $\left[\mathrm{J} \mathrm{mol}^{-1} \mathrm{~K}^{-1}\right]$, and $T$ is the temperature $[\mathrm{K}]$.

\section{Materials}

In order to understand the physical properties of ethylenemethacrylic acid copolymer (Figure 4), the properties of the homopolymers should be discussed shortly.

Whereas the nonpolar hydrophobic polyethylene does not solve in any common solvent and therefore has to be melt-extruded to give foils, tubes, isolations and containers for food packages, the polar, hydrophilic, and in most cases the water soluble polyacrylic acid and polymethacrylic acid

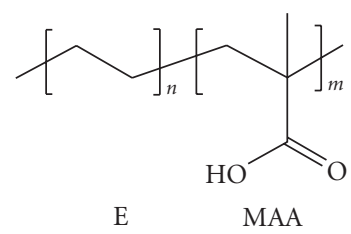

FIGURE 4: Ethylene-methacrylic acid copolymer (E-MAA).

are used as super absorbers (if partially cross-linked) in cosmetic, textile, and paper additives as well as for the production of industrial glues. The most important and interesting property of ethylene methacrylic acid copolymer is the functional groups $(-\mathrm{COOH})$ which can be modified by polymer-analogous reactions.

As basic material for the preparation of cross-linked membranes, two different types of ethylene-methacrylic acid copolymer have been investigated, which differ exclusively in the content of methacrylic acid monomer. In Table 1 the basic polymers used are listed.

\subsection{Preparation of Cross-Linked Membranes}

Cross-linked membranes were obtained by using the two different basic copolymers E-MAA 27 and E-MAA 38 as basic materials. As cross-linking agents, various cross-linkers were applied as listed in Table 2 .

\subsection{Ionical Cross-Linking}

During the cross-linking reaction with aluminium acetyl acetonate, the low volatile acetyl acetone is set free and an ionically cross-linked membrane structure, as shown schematically in Figure 5, is obtained.

It has been found before that ionically cross-linked structures made from rubbery or glassy carboxylic acid containing copolymers can be used very successfully as membranes in different applications [34].

\subsection{Covalently Cross-Linked Structures}

In this work also covalent cross-linked structures were investigated. As cross-linking agents, an aromatic diamine, 2,3,5,6-tetramethyl-1,4-phenylene diamine, and different diand triepoxides as shown in Table 2 were used. As an example for the formation of a covalently cross-linked copolymer structure in Figure 6 the reaction of the carboxylic acids on the polymer backbone with diexpoxides to di- $\beta$ hydroxyesters is shown.

For the preparation of ionically and covalently crosslinked membranes, $0.9 \mathrm{~g}$ of the E-MAA copolymer was dissolved in $10 \mathrm{~mL}$ of tetrahydrofuran (THF). In all cases, an equimolar amount of cross-linker calculated on the desired cross-linking degree was dissolved in $5 \mathrm{~mL}$ of THF. After complete dissolution of the polymer, the cross-linking solution was added and the clear solution was stirred for another 30 minutes, filtered and casted on a polyethylene terephthalate (PET) foil into a glass ring having a diameter 
TABLE 1: Basic copolymers used in this work.

\begin{tabular}{cccccccc}
\hline Copolymer & Composition $[\mathrm{mol} \%]$ & \multicolumn{2}{c}{ Composition $[\mathrm{wt} \%]$} & Titratable acid ${ }^{*}$ Melting temperature $[\mathrm{K}]$ & $\begin{array}{c}\text { Recrystallization } \\
\text { temperature }[\mathrm{K}]^{* *}\end{array}$ \\
\hline & E & MAS & E & MAS & mmol/g golymer & 349 & $313-325$ \\
E-MAA 27 & 89.1 & 10.9 & 72.8 & 27.2 & $3,16^{*}$ & 343 & $-7^{*}$ \\
E-MAA 38 & 83.1 & 16.9 & 61.5 & 38.5 & $4,47^{*}$ & 343 \\
\hline
\end{tabular}

* Measured by potentiometric titration according to DIN 53042;

** Measured by DSC.

TABLE 2: Cross-linking agents used.

Cross-linker

of $12.4 \mathrm{~cm}$. The membranes were covered with glass funnels to keep away dust particles and dried for 12 hours at room temperature inside the hood. For the cross-linking reaction, the membranes were placed in the vacuum oven rising the temperature from $333 \mathrm{~K}$ to $393 \mathrm{~K}$ and lowering the vacuum from 500 to $50 \mathrm{mbar}$ within two hours. The membrane samples were kept another 24 hours at the same conditions inside the vacuum oven. After this procedure, clear, noncolored ionically as well as covalently cross-linked membranes were obtained. The membrane thickness of the different samples determined with a micrometer was between $46 \mu \mathrm{m}$ and $69 \mu \mathrm{m}$.

It was found that cross-linked membranes E-MAA 27 as well as E-MAA 38 cross-linked with aluminium acetyl acetonate, glycerine diglycidylether, and 2,3,5,6-tetramethyl1,4-phenylene diamine, respectively, were nonsoluble in THF which was used for the membrane preparation. NMR spectroscopic investigations of the cross-linked polymers were not possible as a result of the insolubility of the cross-linked materials. In solid-state NMR, the protons of the cross-links tend to disappear in the baseline. A qualitative or quantitative evaluation of the conducted cross-linking reactions using IR spectroscopy was carried out but thereby only slight tendencies but no quantitative correlation have been found. From other inquiries of esterifications via the acid chloride of E-MAA 27, carboxylic groups with isopropanol we found out that if less than $20 \%$ of the carboxyl groups are esterified, it is not possible with an adequate reliability to detect the crosslinks. Over 20\% nice qualitative correlations have been seen. However, it has been shown that the cross-linking reaction is reproducible and leads to membranes with reproducible separation characteristics. Experiments have been performed with different membrane samples from the same batch, as well as membrane samples prepared independently from each other.

\section{Pervaporation Apparatus and Analytical Method}

For the pervaporation measurements a slightly modified standard apparatus, described elsewhere in detail, was used $[24,35]$. The effective membrane area was $41.9 \mathrm{~cm}^{2}$ and the downstream pressure was kept at 15-30 mbar. After steady state has been reached, feed and permeate samples have been collected every 2 hours, the flux has been calculated by weighing the cold traps and the enrichment factor was determined by cooling the feed and permeate compositions by HPLC. For that purpose, the permeate samples, which were phase-separated in most of the cases, had to be homogenized with acetone. Afterwards, $4 \mu \mathrm{L}$ of the samples have been mixed with $1 \mathrm{~mL}$ of water and injected into the HPLC column. The solvent of the HPLC was 70/30 acetonitril/water, whereas $0.1 \mathrm{wt} \%$ of trifluoro acetic acid was added to the water to prevent the formation of phenolate on the HPLC column. The flux on the column was $0.7 \mathrm{~mL} / \mathrm{min}$, and the wave length of the detector was $215 \mathrm{~nm}$. As HPLC column, a nonpolar C18 standard column was used. With this method, the retention time of phenol was 4.14 minutes.

In order to ensure reproducible results, pervaporation data were measured at least with three different membrane samples. For the E-MAA 27 and E-MAA 38, respectively, 

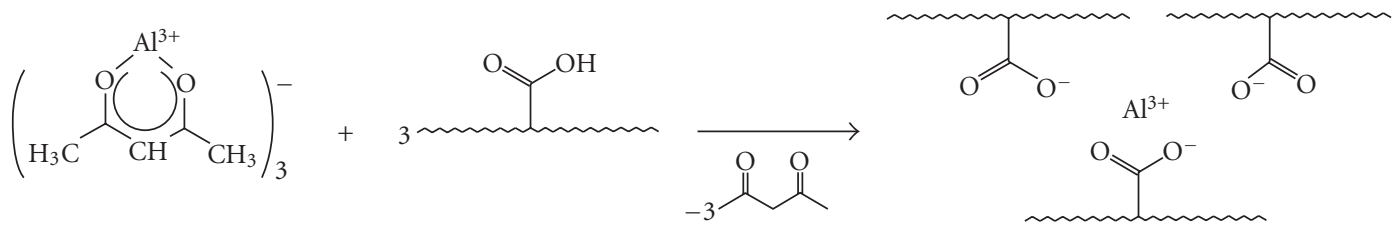

Polymer backbone

FIgURE 5: Schematic formation of ionical cross-linked membranes [23].

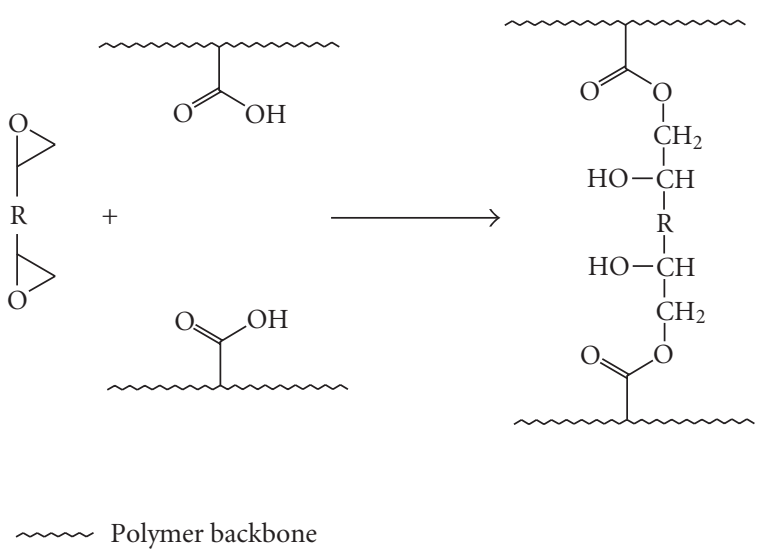

FIGURE 6: Schematic formation of covalent cross-linking.

used in this work as well as for other polymeric materials investigated in our group, it was found that the deviation in flux and selectivtiy is $\pm 10 \%$ [36-38] for independently prepared membrane samples. This is in good agreement with deviations of industrial produced membranes.

\section{Results and Discussion}

First of all, the two basic polymeric materials E-MAA 27 and E-MAA 38 should be tested if they are in principle suitable materials for the removal of phenol from aqueous solutions, and if cross-linking is indeed necessary. Figure 7 shows the separation characteristics of E-MAA 27 with a methacrylic acid monomer content of $27.2 \mathrm{wt} \%$ at $313 \mathrm{~K}$. In Figure $7(\mathrm{a})$, the total flux, and the partial phenol fluxes, and water fluxes are plotted versus the phenol concentration in the feed mixture. With increasing phenol content in the feed, the flux shows a linear increase due to swelling effects in the membrane material. Although the concentration of phenol in the permeate did not change significantly with increasing phenol concentration in the feed, the separation factor shows a significant decrease with increasing phenol concentration, as shown in Figure 7(b). The phenomenon of increasing flux with decreasing selectivity is very common and has been observed before in many studies concering pervaporation but also gas permeation using swelling feed components (e.g., aromatics, sulphur-aromatics, phenol, ethylene oxid, and $\mathrm{CO}_{2}$ [39-41]. With increasing concentration of the swelling component), increasing rearrangement of polymer chains is assumed with increasing chain mobility. As a result of this, the flux increases. According to the increased chain mobility reached during swelling, the diffusion coefficients of the different permeating components are changing. In the case of water/phenol, the diffusion rate of the small water molecules accelerates much more compared to the diffusion rate of phenol.

In order to show that the swelling of the E-MAA 27 polymer is due to an increase in phenol concentration sorption measurements have been performed exemplarily. Therby binary mixtures of phenol/water have been prepared in different concentrations excluding the miscibility gap. For each sorption experiment, three different membrane samples with an average weight of $150 \mathrm{mg}$ were used. The deviation of the averaged mass uptake of each set of samples was $\pm 10 \%$.

As the data in Table 3 show, the mass uptake is strongly dependent on phenol concentration. If pure water is used, the mass uptake is only $0.3 \mathrm{wt} \%$ for the E-MAA 27 whereas the mass uptake in a $3 \mathrm{wt} \%$ phenol/water solution was three times higher. If very high phenol concentrations (75 wt\%) are applied, the effect continues and the mass uptake is $6.2 \%$.

In order to investigate the phenol and water concentration inside of the membrane, a photometric method was applied based on the oxidative coupling of phenol with 1methyl-2-benzothiazonlinone hydrazon as already described in $[42,43]$, which is a commercially applied test for phenol in aqueous solutions according to EPA 420.1, US Standard methods 5530 and ISO 6439. Further details are found in [36].

As also shown in Table 3, the basic membrane material shows strong affinity towards phenol. For example, if the EMAA 27 membrane is exposed to a $3 \mathrm{wt} \%$ a phenol/water solution, a mass uptake of $83 \mathrm{wt} \%$ phenol in the membrane has been found. At $7 \mathrm{wt} \%$ phenol/water solution an even higher mass uptake of $88 \mathrm{wt} \%$ was observed. Based on the results of partial phenol and water mass uptakes, the solubility selectivity $\alpha_{\text {sol }}$ is calculated based on (5) as the ratio of weight fractions inside the membrane divided by the ratio of weight fractions in solution. Analogous to (5), the weight fraction of the preferred sorbed substance belongs to the numerator. Thereby values of $\alpha_{\text {sol }}$ between 98 and 157 have been determined. The overall selectivity of a membranebased process is defined as the product of solubility selectivity and diffusivity selectivity according to the solution-diffusion mechanism. However, the kinetic diameter of the phenol is 


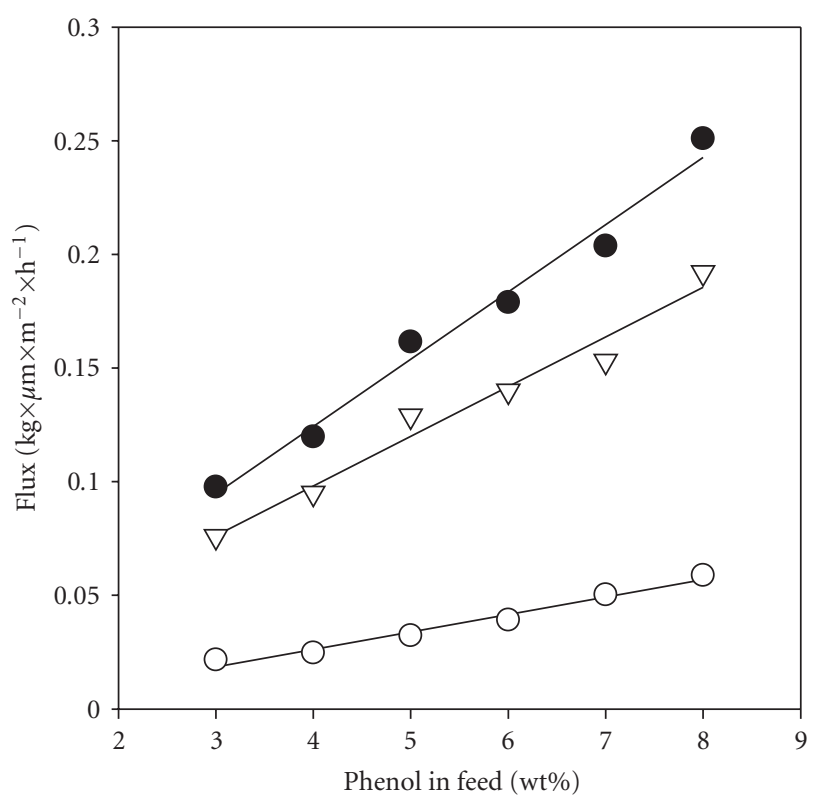

(a)

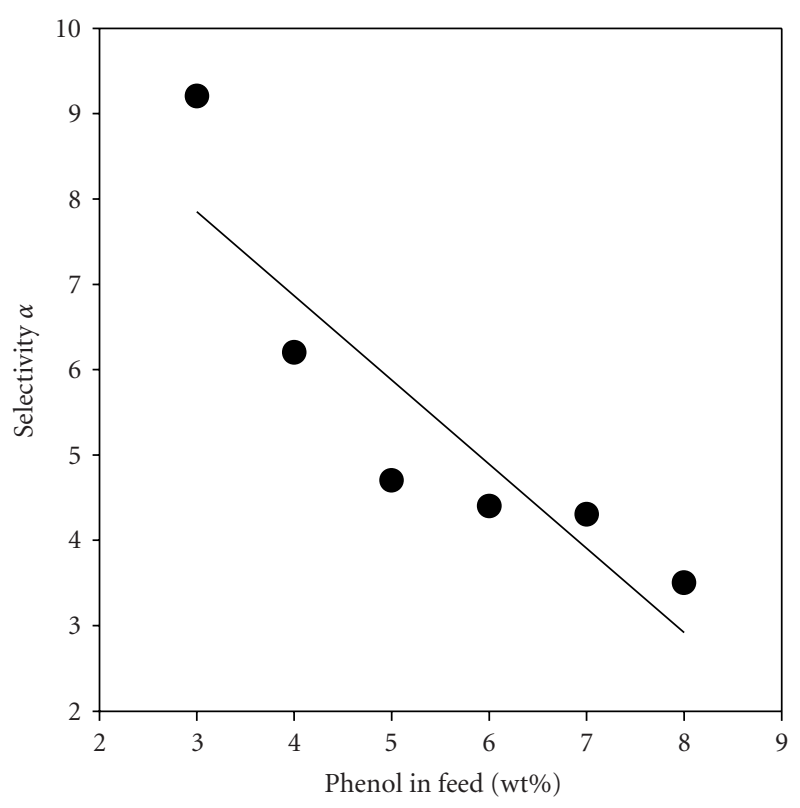

(b)

Figure 7: (a) Total flux $(\bullet)$, partial water flux $(\nabla)$, and partial phenol flux $(\bigcirc)$ and $(b)$ separation factor with increasing phenol concentration in the feed mixture for the E-MAA 27 at $313 \mathrm{~K}$ and a permeate pressure of 15-30 mbar.

TABLE 3: Mass uptake of E-MAA 27 in different composed phenol/water mixtures.

\begin{tabular}{lccccc}
\hline Copolymer & Composition phenol/water $[\mathrm{wt} \%]$ & Total uptake $[\mathrm{wt} \%]$ & wt $\%$ phenol & - \\
\hline \\
E-MAA 27 & 0 & 100 & 0.3 & 0.9 & 83 \\
& 3 & 97 & 3.8 & 88 & 17 \\
& 7 & 93 & 6.2 & 91 & 12 \\
\hline
\end{tabular}

*Compared to dry polymer before exposure to phenol/water mixture at room temperature.

much larger compared to the water molecule and so the diffusivity selectivity has to be smaller than 1 . Since experimentally phenol enrichment has been observed it is obvious that the process is solubility controlled. This is in good accordance with many other liquid/liquid membrane-based separation processes as aromatic/aliphatic and water/ethanol separations. Due to the fact that with cross-linking the chain mobility is reduced, the diffusion coefficient of phenol is also lowered. Therefore, an increase of selectivity with crosslinking has to be an effect of increased solubility selectivity.

By increasing the methacrylic acid content in the polymer structure, the copolymer was expected to be more versatile to swelling effects in phenol/water mixtures. As shown in Figure 8(a) with the E-MAA 38, containing a methacrylic acid content of $38.5 \mathrm{wt} \%$, the fluxes do not increase linearly but exponentially with increasing phenol concentration in the feed solution. At phenol feed concentrations of $7 \mathrm{wt} \%$, the total flux of the E-MAA 38 is 3.4 times higher compared to the E-MAA 27 membrane. At the same time, the phenol flux of the E-MAA 38 is merely higher by 1.6 times compared to the E-MAA 27. This is due to the increase in hydrophilicity, which is caused by the higher content of methacrylic acid monomer in the E-MAA 38 compared to the E-MAA 27.
Similar effects of increasing water fluxes with increasing hydrophilicity of the polymer backbone have been also observed for different polymer classes [44].

\subsection{Conditioning Effects on Noncross-Linked Membranes}

Conditioning effects have been investigated in earlier work with polyimide membranes $[4,25,45]$ and it was shown that durable effects leading to increased fluxes and increased separation factors have been observed. Investigating various conditioning experiments by using different polymers led to the result that the membrane performance did not change even after several measuring cycles if once a maximum feed concentration of the swelling component was applied [38].

The aim of this work was to investigate if similar conditioning effects for the rubbery E-MAA 38 membrane compared to the glassy polyimides can be reached or if undesirable changes of the membrane performance (e.g., loss in selectivity) will occur.

Therefore, pervaporation experiments with the E-MAA 38 membrane were once performed with increasing phenol 


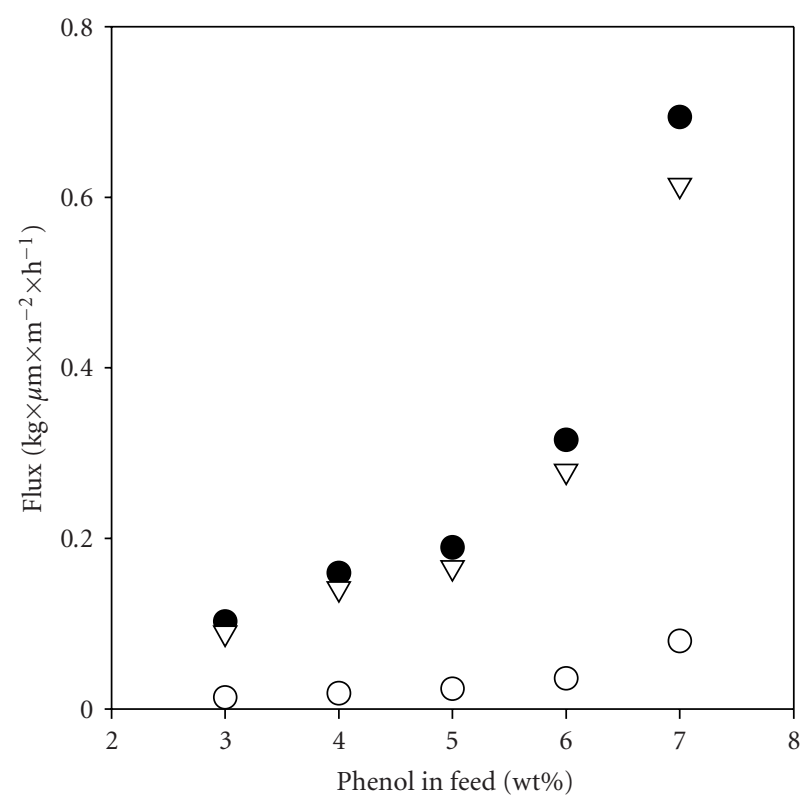

(a)

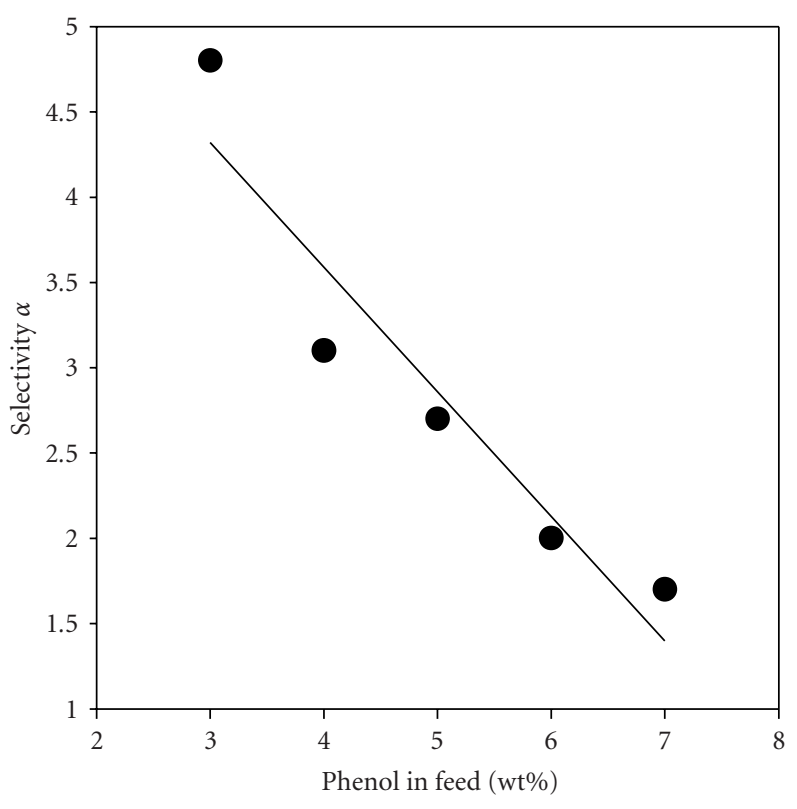

(b)

Figure 8: (a) Total flux $(\bullet)$, partial water flux $(\nabla)$, and partial phenol flux $(\bigcirc)$ and (b) selectivity with increasing phenol concentration in the feed mixture for the E-MAA 38 at $313 \mathrm{~K}$ and a permeate pressure of 15-30 mbar.

concentration and after reaching the highest possible phenol concentration in feed, the concentrations were lowered stepwise. The results are shown in Figure 9. After reaching the highest phenol concentration, the total fluxes on the back-measurements were slightly higher compared to the first measurements. It is also obvious from Figure 9, that the separation factors are much higher when the membrane once was exposed to high phenol concentration. So the observed effects described here are conditioning effects which can be used to increase the performance of a membrane material. Such effects have also been observed on other membrane materials (i.e., copolyimides and carboxylic acid containing copolyimides) $[3,4,25,38,45]$.

\subsection{Comparison of Different Cross-Linking Agents}

Using E-MAA 38 as well as E-MAA 27 as a basic membrane material, different cross-linking agents as well as different concentrations of cross-linking agents have been investigated in order to figure out their influence on the separation characteristics. Thereby all experiments have been performed at a feed concentration of $8 \mathrm{wt} \%$, the membrane temperature was at $313 \mathrm{~K}$, and the permeate pressure was kept at 15-30 mbar.

In Figure 10, the results for E-MAA 38 membranes with a methacrylic acid content of $38.5 \mathrm{wt} \%$, noncross-linked, covalently as well as ionically cross-linked are shown. It can be seen that ionical and covalent cross-linking result in a reduction of fluxes. This is due to the fact that cross-linking leads to a lower mobility of the polymer backbone and so the permeation rate for the single components is lowered.
At the same time, the cross-linked membranes showed all higher separation factors compared to the noncross-linked membrane.

From all cross-linkers investigated, the ionic cross-linker aluminium acetyl acetonate seemed to result in the highest separation factor and therefore it was also investigated with the E-MAA 27 membrane having a lower methacrylic acid content of $27.2 \mathrm{wt} \%$ compared to $38.5 \mathrm{wt} \%$ in the E-MAA 38. For the membranes with the lower content of carboxylic acid groups, the effects on fluxes and separation factor were much higher. In Figure 11, it can be seen that separation factors of up to 6.0 can be reached with the ionically cross-linked membrane.

From the solubility data in Table 3 , it is obvious that the diffusivity selectivity has to be much lower than 1 . During cross-linking, the chain mobility is reduced and therefore the diffusivity selectivity for phenol in aqueous solution is lowered. The experimental increase in selectivity can only be explained by an increase of solubility selectivity in the crosslinked material.

\subsection{Temperature Dependency of the Separation Performance}

In the following experiments, it was investigated how changes of temperature affects the separation characteristics. As a membrane material, E-MAA 27 cross-linked ionically $(10 \%)$ with aluminium acetyl acetonate was chosen. From Figure 12, it is obvious that an exponential increase in fluxes is obtained. It is also interesting that at low feed temperatures, the partial phenol fluxes are significantly 


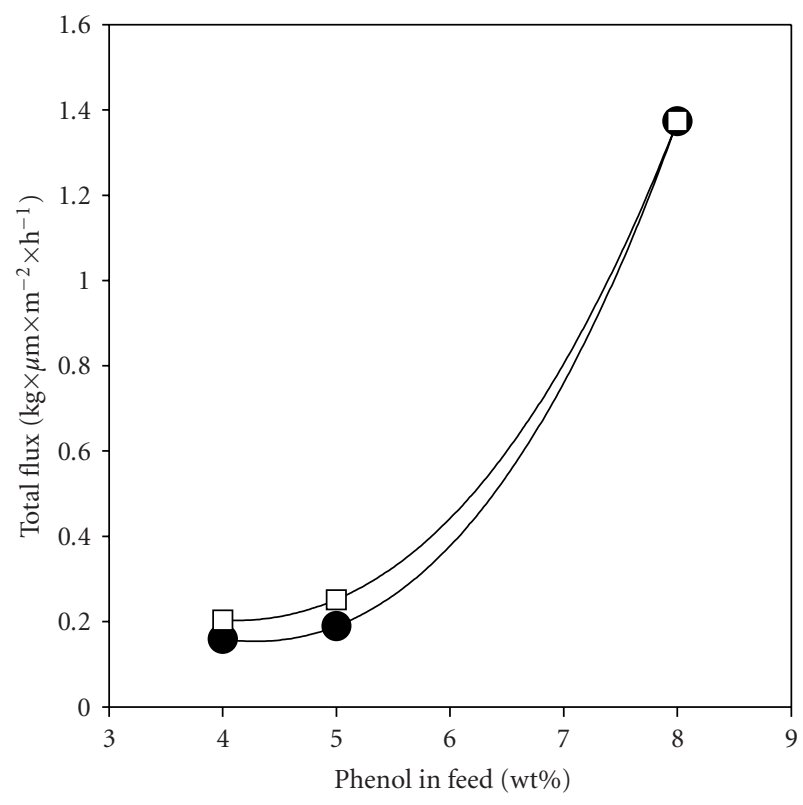

(a)

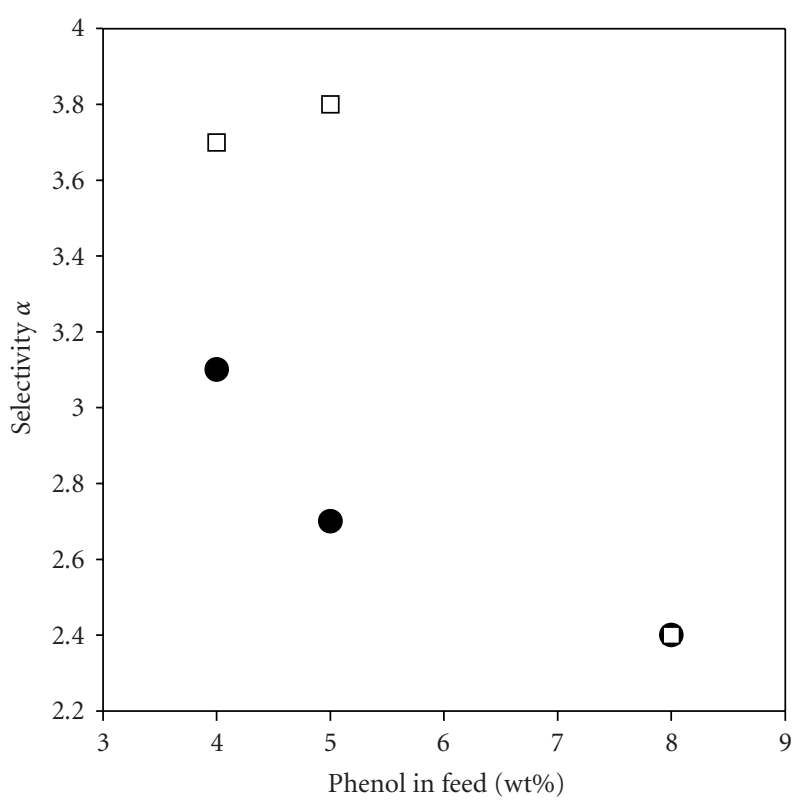

(b)

FIgURE 9: (a) Total flux in pervaporation experiments performed with increasing phenol concentration in feed $(\bullet)$ as well as decreasing phenol concentration ( $\square$ ) and (b) separation factor with increasing phenol concentration in the feed mixture $(\bullet)$ as well as decreasing phenol concentration $(\square)$ for the E-MAA 38 at $313 \mathrm{~K}$ and a permeate pressure of $15-30$ mbar.

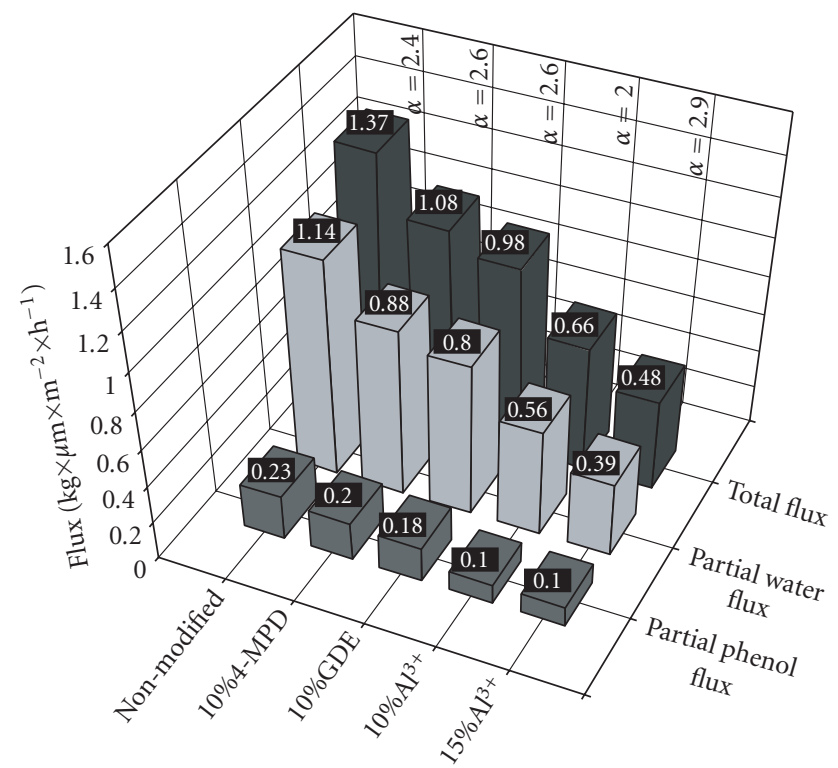

Figure 10: E-MAA 38 copolymer cross-linked covalently with $10 \%$ 4MPD (2,3,5,6-tetramethyl-1,4-phenylene diamine), 10\% GDE (glycerine diglycidylether) and ionically using $10 \%$ and $15 \% \mathrm{Al}^{3+}$, feed concentration $8 \mathrm{wt} \%$ phenol, membrane temperature $313 \mathrm{~K}$.

lower than the partial water fluxes through the membrane. Whereas at feed temperatures higher than $373 \mathrm{~K}$, the phenol fluxes are slightly higher than the water fluxes, resulting in very high separation factor as also shown in Figure 12.

The exponential increase of flux with increasing temperature is assumed to be attributed to (i) increase in

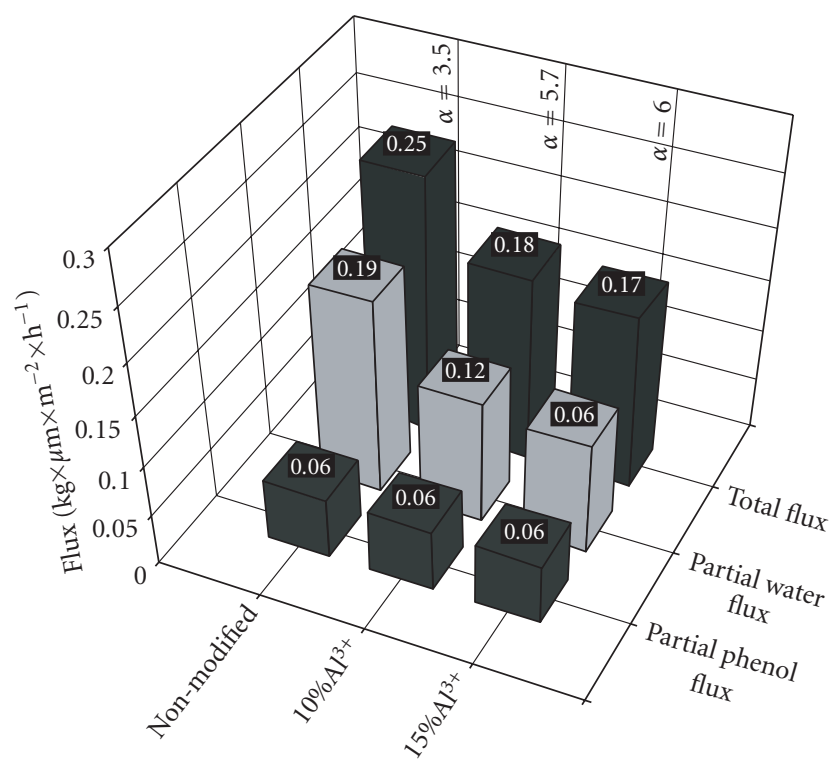

FIgURE 11: E-MAA 27 copolymer cross-linked ionically using $10 \%$ and $15 \% \mathrm{Al}^{3+}$, feed concentration $8 \mathrm{wt} \%$ phenol, membrane temperature $313 \mathrm{~K}$.

solubility with temperature, (ii) increase of diffusivity with temperature, and (iii) increase in diffusivity of the components due to increased swelling of the polymer material. Detailed explanation on the theory and calculations of exponential increase of fluxes with increasing temperatures can be found in [23]. According to the solution-diffusion 


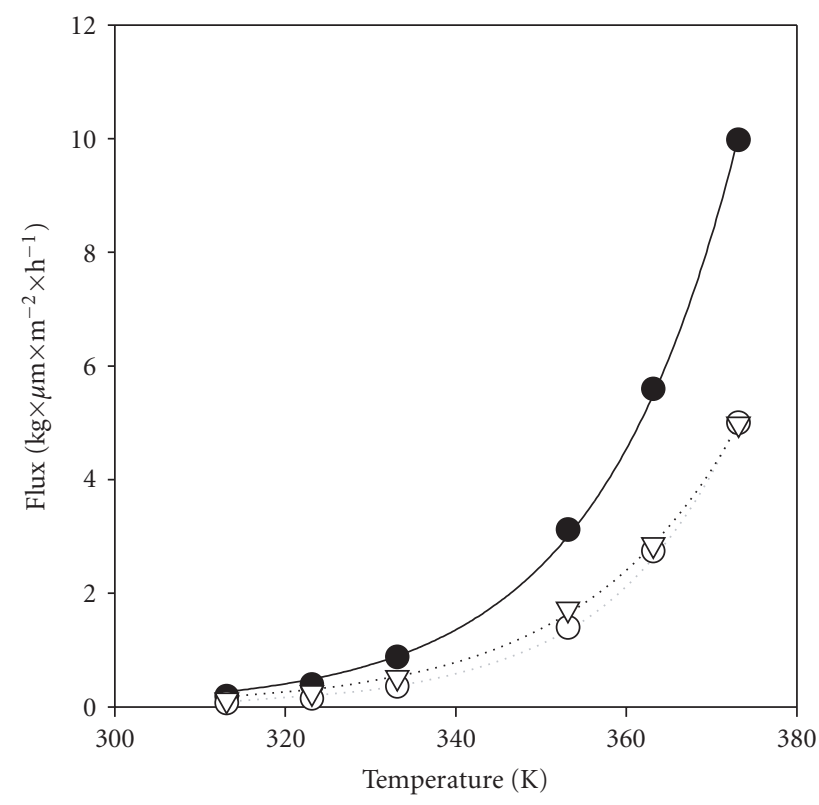

(a)

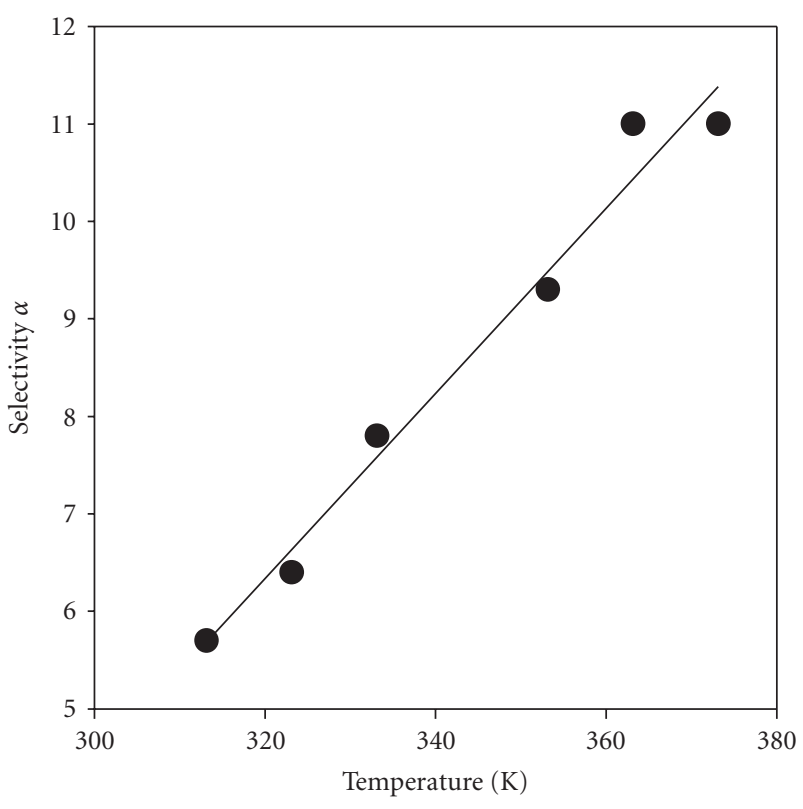

(b)

Figure 12: (a) Temperature-dependent pervaporation experiments (8 wt\% phenol in feed) with an E-MAA 27 membrane ionically crosslinked with $10 \% \mathrm{Al}^{3+}$, total flux $(\bullet)$, partial water flux $(\nabla)$, and partial phenol flux $(\bigcirc)$ and $(\mathrm{b})$ separation factor.

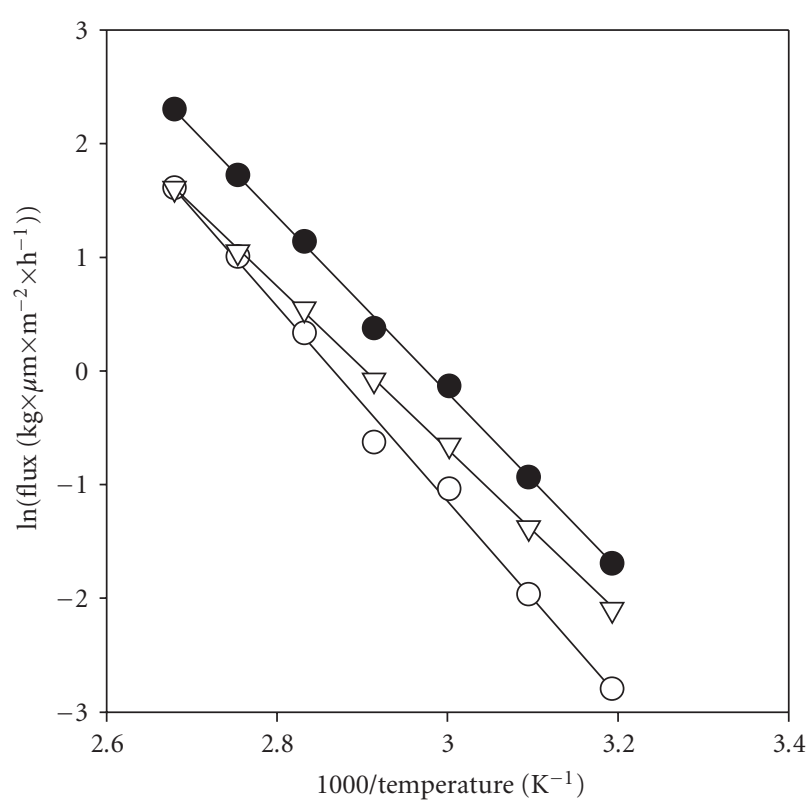

Figure 13: Arrhenius plot (8 wt \% phenol in feed) with an E-MAA 27 membrane ionically cross-linked with $10 \% \mathrm{Al}^{3+}$, total flux $(\bullet)$, partial water flux $(\nabla)$, and partial phenol flux $(\bigcirc)$.

model as shown in Figure 3, inside of the polymer layer gradients of concentration, swelling effects as well as pressure differences are occuring. It is assumed that only in a minor part of the membrane layer, faced to the permeate side, low pressures as those applied on the permeate side are existing. The major part of the polymer layer is wet and/or swollen. Therefore, the exponential increase in flux is not attributed to increase in vapor saturation, since phenol, for example, has a boiling point of $181.9^{\circ} \mathrm{C}$, whereas temperature-dependent pervaporation measurements have been performed between $30^{\circ} \mathrm{C}$ and $100^{\circ} \mathrm{C}$.

\subsection{Activation Energy for Permeation}

According to (6) and the Arrhenius plot in Figure 13, the partial fluxes can be plotted versus $1 / T$ and the activation energies for the permeation of phenol and water can be calculated.

The activation energy for permeation consists of two terms, the enthalpie of solution (phenol and water, resp., in the membrane) and the activation energy for diffusion. Whereas the activation energy for the diffusion is always positive, the enthalpie of solution can be positve, or negative. For the system water/phenol investigated in this work, for the activation energy of permeation positive values are obtained.

The activation energy for diffusion is considered as the energy that is necessary to form microvoids of adequate size for the permeating molecules. Cohesion forces of the polymer chains are counteracting against microvoid formation. High cohesion forces denote high activation energy for the diffusion. If large molecules (e.g., phenol) are permeating, larger microvoids are necessary, and therefore a higher activation energy for diffusion occurs. It was found that for rubbery polymers the activation energy for diffusion increases linearly with the size of the molecules [46].

For the E-MAA 27, which is also a rubbery polymer, activation energies for the permeation of phenol of $E_{J}=$ $71.3 \mathrm{~kJ} / \mathrm{mol}$, water of $59.7 \mathrm{~kJ} / \mathrm{mol}$, and the mixture of $8 \mathrm{wt} \%$ of phenol in feed $64.49 \mathrm{~kJ} / \mathrm{mol}$ were obtained. Thereby 
phenol has the highest activation energy for permeation, due to the fact that it is the component with the largest kinetic diameter. With the activation energy the experimental data of increasing enrichment factors with increasing feed temperature can be explained.

\section{Conclusion}

(i) The nonmodified ethylene-methacrylic acid copolymer showed increasing fluxes and decreasing separation factors with increasing phenol content at $310 \mathrm{~K}$.

(ii) With increasing methacrylic acid content in the polymers higher fluxes and lower enrichment factors were observed.

(iii) It has been shown that conditioning of ionically cross-linked ethylene-methacrylic acid copolymer membranes is possible leading to enhanced separation characteristics for the phenol/water separation.

(iv) Cross-linking generally leads to higher separation factors combined with lower fluxes due to the reduced mobility of the polymer backbone. This effect is stronger for the copolymer having the lower methacrylic acid content.

(v) For the ionically cross-linked ethylene-methacrylic acid copolymer membrane a strong increase in enrichment factor as well as an exponential increase in flux with increasing temperature is observed.

(vi) The activation energy of phenol was found to be higher by $11 \mathrm{~kJ} / \mathrm{mol}$ compared to water which explains the enhanced separation characteristics at higher temperature.

\section{Acknowledgment}

The authors gratefully acknowledge the SFB 663 as well as BASF for providing the basic polymer materials as well as cross-linking components.

\section{References}

[1] H. Strathmann, "Membrane separation-recent developments and new opportunities," in Proceedings of the AIChE Annual Meeting, pp. 16-21, Los Angeles, Calif, USA, November 1997.

[2] R. L. Burns and W. J. Koros, "Defining the challenges for $\mathrm{C}_{3} \mathrm{H}_{6} / \mathrm{C}_{3} \mathrm{H}_{8}$ separation using polymeric membranes," Journal of Membrane Science, vol. 211, no. 2, pp. 299-309, 2003.

[3] D. Katarzynski, Auftrennung von Kohlenwasserstoffgemischen durch Polymermem-branen, Diplomarbeit, Universität Düsseldorf, Dusseldorf, Germany, 2004.

[4] D. Katarzynski and C. Staudt, "Permeation properties of different aromatic substances in multicomponent aromatic/aliphatic pervaporation experiments," Desalination, vol. 200, no. 1-3, pp. 23-25, 2006.

[5] R. Qi, C. Zhao, J. Li, Y. Wang, and S. Zhu, "Removal of thiophenes from $n$-octane/thiophene mixtures by pervaporation," Journal of Membrane Science, vol. 269, no. 1-2, pp. 94-100, 2006.
[6] R. Qi, Y. Wang, J. Li, C. Zhao, and S. Zhu, "Pervaporation separation of alkane/thiophene mixtures with PDMS membrane," Journal of Membrane Science, vol. 280, no. 1-2, pp. 545-552, 2006.

[7] S. Das, A. K. Banthia, and B. Adhikari, "Pervaporation separation of aqueous chlorophenols by a novel polyurethane urea-poly (methyl methacrylate) interpenetrating network membrane," Journal of Membrane Science, vol. 280, no. 1-2, pp. 675-683, 2006.

[8] J. Sawai, N. Ito, T. Minami, and M. Kikuchi, "Separation of low volatile organic compounds, phenol and aniline derivatives, from aqueous solution using silicone rubber membrane," Journal of Membrane Science, vol. 252, no. 1-2, pp. 1-7, 2005.

[9] A. Livingston, F. C. Ferreira, S. Han, A. Boam, and S. Zhang, "Membrane aromatic recovery system (MARS) - a new process for recovering phenols and aromatic amines from aqueous streams," in Proceedings of the 12th Annual Meeting of the North American Membrane Society (NAMS '01), Lexington, Ky, USA, May 2001.

[10] F. C. Ferreira, S. Han, and A. G. Livingston, "Recovery of aniline from aqueous solution using the membrane aromatic recovery system (MARS)," Industrial \& Engineering Chemistry Research, vol. 41, no. 11, pp. 2766-2774, 2002.

[11] W. Kujawski, A. Warszawski, W. Ratajczak, T. Porębski, W. Capała, and I. Ostrowska, "Removal of phenol from wastewater by different separation techniques," Desalination, vol. 163, no. 1-3, pp. 287-296, 2004.

[12] F. C. Ferreira, S. Han, A. Boam, S. Zhang, and A. G. Livingston, "Membrane aromatic recovery system (MARS): lab bench to industrial pilot scale," Desalination, vol. 148, no. 1-3, pp. 267$273,2002$.

[13] T. Uragami, H. Yamada, and T. Miyata, "Removal of dilute volatile organic compounds in water through graft copolymer membranes consisting of poly(alkylmethacrylate) and poly(dimethylsiloxane) by pervaporation and their membrane morphology," Journal of Membrane Science, vol. 187, no. 1-2, pp. 255-269, 2001.

[14] W. Kujawski, A. Warszawski, W. Ratajczak, T. Porębski, W. Capała, and I. Ostrowska, "Application of pervaporation and adsorption to the phenol removal from wastewater," Separation and Purification Technology, vol. 40, no. 2, pp. 123132, 2004.

[15] P. Wu, R. W. Field, R. England, and B. J. Brisdon, "A fundamental study of organofunctionalised PDMS membranes for the pervaporative recovery of phenolic compounds from aqueous streams," Journal of Membrane Science, vol. 190, no. 2, pp. 147-157, 2001.

[16] S. Mielczarski, A. Noworyta, M. Kubasiewicz-Ponitka, and P. Suchecki, "Treatment of phenol wastewater using pervaporation," Environment Protection Engineering, vol. 31, no. 3-4, pp. 23-31, 2005.

[17] M. Krea, D. Roizard, N. Moulai-Mostefa, and D. Sacco, "New copolyimide membranes with high siloxane content designed to remove polar organics from water by pervaporation," Journal of Membrane Science, vol. 241, no. 1, pp. 55-64, 2004.

[18] N. C. Pradhan, C. S. Sarkar, S. Niyogi, and B. Adhikari, "Separation of phenol-water mixture by membrane pervaporation using polyimide membranes," Journal of Applied Polymer Science, vol. 83, no. 4, pp. 822-829, 2001.

[19] F. Pithan and C. Staudt-Bickel, "Crosslinked copolyimide membranes for phenol recovery from process water by pervaporation," ChemPhysChem, vol. 4, no. 9, pp. 967-973, 2003. 
[20] B. Sinha, U. K. Ghosh, N. C. Pradhan, and B. Adhikari, "Separation of phenol from aqueous solution by membrane pervaporation using modified polyurethaneurea membranes," Journal of Applied Polymer Science, vol. 101, no. 3, pp. 1857$1865,2006$.

[21] T. Gupta, N. C. Pradhan, and B. Adhikari, "Synthesis and performance of a novel polyurethaneurea as pervaporation membrane for the selective removal of phenol from industrial waste water," Bulletin of Materials Science, vol. 25, no. 6, pp. 533-536, 2002.

[22] J. D. Wind, C. Staudt-Bickel, D. R. Paul, and W. J. Koros, "The effects of crosslinking chemistry on $\mathrm{CO}_{2}$ plasticization of polyimide gas separation membranes," Industrial and Engineering Chemistry Research, vol. 41, no. 24, pp. 6139-6148, 2002.

[23] S. Matsui and D. R. Paul, "Pervaporation separation of aromatic/aliphatic hydrocarbons by crosslinked poly(methyl acrylate-co-acrylic acid) membranes," Journal of Membrane Science, vol. 195, no. 2, pp. 229-245, 2002.

[24] A. Mixa, Polymermembranen bei der Entfernung organischer Schadstoffe in der Prozesswasseraufbereitung, Diplomarbeit, Universität Düsseldorf, Dusseldorf, Germany, 2005.

[25] J. Ren, C. Staudt-Bickel, and R. N. Lichtenthaler, "Separation of aromatics/aliphatics with crosslinked 6FDA-based copolymides," Separation and Purification Technology, vol. 2223, pp. 31-43, 2001.

[26] M. Lamers, Steuerung der Trenneigenschaften polymerer Membranen durch supramolekulare Komplexbildung mit Cyclodextrinen, Dissertation, Universität Düsseldorf, Dusseldorf, Germany, 2007.

[27] T. Graham, "On the absorption and dialytic separation of gases by colloid septa," Philosophical Magazine, vol. 32, no. 218, pp. 401-420, 1866.

[28] J. G. Wijmans and R. W. Baker, "The solution-diffusion model: a review," Journal of Membrane Science, vol. 107, no. 1-2, pp. 1-21, 1995.

[29] T. C. Merkel, V. I. Bondar, K. Nagai, B. D. Freeman, and I. Pinnau, "Gas sorption, diffusion, and permeation in poly(dimethylsiloxane)," Journal of Polymer Science Part B, vol. 38, no. 3, pp. 415-434, 2000.

[30] A. Fick, "On liquid diffusion," Annalen der Physik, vol. 170, no. 1, pp. 59-86, 1855.

[31] P. J. A. M. Kerkhof, "A modified Maxwell-Stefan model for transport through inert membranes: the binary friction model," The Chemical Engineering Journal and the Biochemical Engineering Journal, vol. 64, no. 3, pp. 319-343, 1996.

[32] F. Fornasiero, J. M. Prausnitz, and C. J. Radke, "Multicomponent diffusion in highly asymmetric systems. An extended Maxwell-Stefan model for starkly different-sized, segmentaccessible chain molecules," Macromolecules, vol. 38, no. 4, pp. 1364-1370, 2005.

[33] K.W. Böddeker, “Terminology in pervaporation," Journal of Membrane Science, vol. 51, no. 3, pp. 259-272, 1990.

[34] "The use of ethylene copolymers for the production of materials for material separation," WO 2005/032710.

[35] T. Gruber, Untersuchungen zum Stofftransport in nichtporösen Polymermembranen, Dissertation, Universität Heidelberg, Heidelberg, Germany, 2000.

[36] A. Mixa, E-MAS: Effiziente polymeranaloge Modifizierung und Charakterisierung zur Anwendung in Membrantrennverfahren, Dissertation, Universität Düsseldorf, Dusseldorf, Germany, 2008.
[37] D. Katarzynski, Abtrennung von mehrkernigen Aromaten aus Aromaten/Aliphatenmischungen, Dissertation, Universität Düsseldorf, Dusseldorf, Germany, 2008.

[38] F. Pithan, Neuartige Copolyimidmembranen für die Pervaporation zum Einsatz in der Aromaten/Aliphaten-Trennung und der Prozesswasseraufbereitung, Dissertation, Universität Heidelberg, Heidelberg, Germany, 2003.

[39] E. S. Sanders, "Penetrant-induced plasticization and gas permeation in glassy polymers," Journal of Membrane Science, vol. 37, no. 1, pp. 63-80, 1988.

[40] A. Bos, I. G. M. Pünt, M. Wessling, and H. Strathmann, "Plasticization-resistant glassy polyimide membranes for $\mathrm{CO}_{2} / \mathrm{CO}_{4}$ separations," Separation and Purification Technology, vol. 14, no. 1-3, pp. 27-39, 1998.

[41] C. Staudt-Bickel and W. J. Koros, "Improvement of $\mathrm{CO}_{2} / \mathrm{CH}_{4}$ separation characteristics of polyimides by chemical crosslinking," Journal of Membrane Science, vol. 155, no. 1, pp. 145-154, 1999.

[42] S. Hüning and K. H. Fritsch, "Azofarbstoffe durch oxydative Kupplung I," Analytical Chemistry, vol. 609, pp. 143-160, 1957.

[43] E. Kamata and N. K. Zashi, "Color reactions of 3-methyl-2benzothiazolone hydrazone with phenol derivatives I," Chemical Abstracts, vol. 65, p. 16052a, 1966.

[44] M. Bennett, B. J. Brisdon, R. England, and R. W. Field, "Performance of PDMS and organofunctionalised PDMS membranes for the pervaporative recovery of organics from aqueous streams," Journal of Membrane Science, vol. 137, no. 1-2, pp. 63-88, 1997.

[45] M. R. Coleman and W. J. Koros, "Conditioning of fluorinecontaining polyimides. 2. Effect of conditioning protocol at $8 \%$ volume dilation on gas-transport properties," Macromolecules, vol. 32, no. 9, pp. 3106-3113, 1999.

[46] G. J. Van Amerongen, "The permeability of different rubbers to gases and its relation to diffusivity and solubility," Journal of Applied Physics, vol. 17, no. 11, pp. 972-985, 1946. 

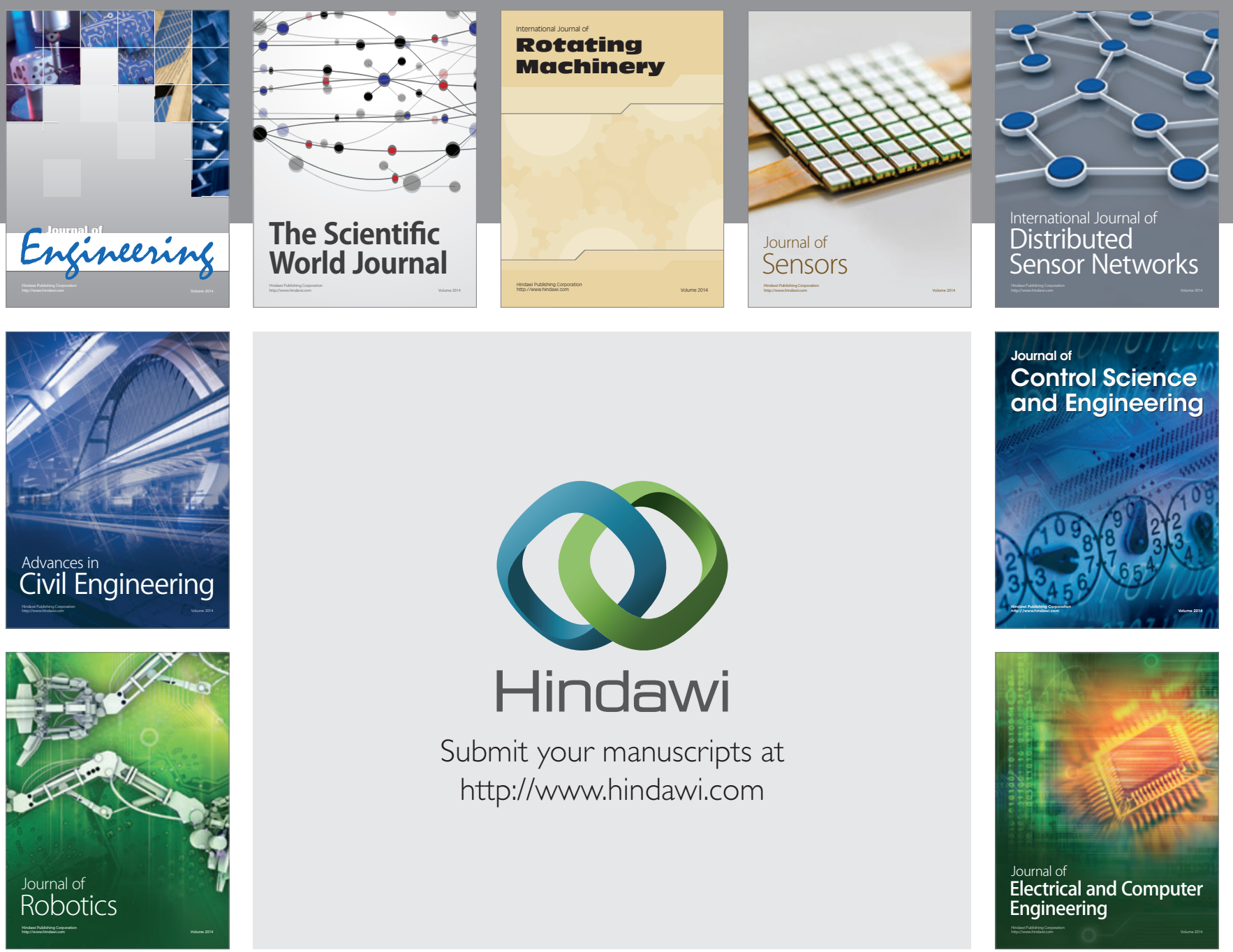

Submit your manuscripts at

http://www.hindawi.com
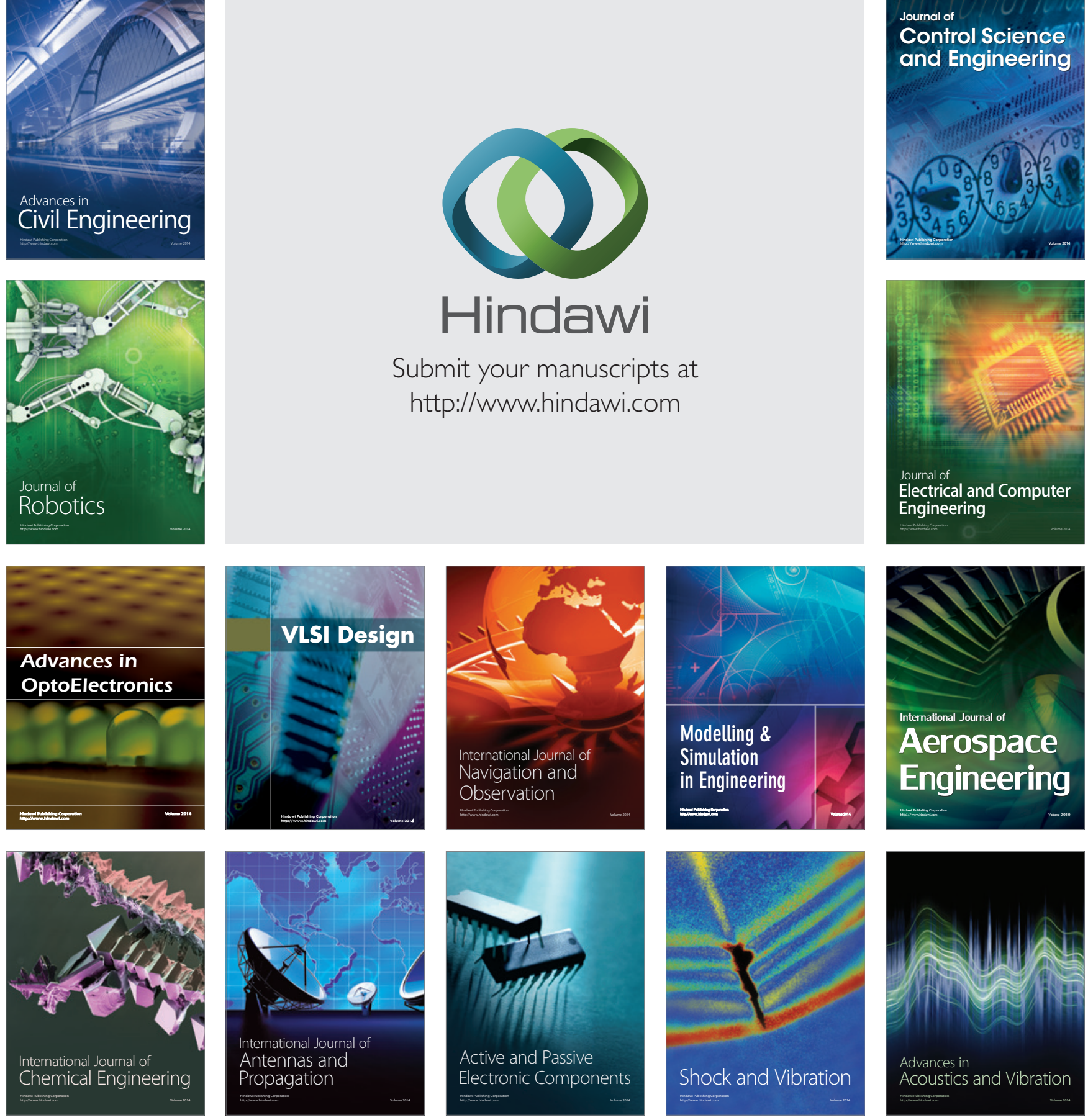